\title{
La Revista Penal y Penitenciaria: órgano de difusión de una burocracia moderna (1936-1946)
}

The Revista Penal y Penitenciaria: organ of diffusion of a modern bureaucracy (1936-1946)

La Revista Penal y Penitenciaria : organe de diffusion d'une bureaucratie moderne (1936-1946))

\section{Jeremías Silva}

\section{(2) OpenEdition}

\section{Journals}

Edición electrónica

URL: http://journals.openedition.org/rhj/2153

DOI: $10.4000 /$ rhj.2153

ISSN: 0719-4153

Editor

ACTO Editores Ltda

Referencia electrónica

Jeremías Silva, "La Revista Penal y Penitenciaria: órgano de difusión de una burocracia moderna

(1936-1946) », Revista Historia y Justicia [En línea], 12 | 2019, Publicado el 29 mayo 2019, consultado el 05 julio 2019. URL : http://journals.openedition.org/rhj/2153 ; DOI : 10.4000/rhj.2153

Este documento fue generado automáticamente el 5 julio 2019.

Revista Historia y Justicia 


\section{La Revista Penal y Penitenciaria: órgano de difusión de una burocracia moderna (1936-1946)}

The Revista Penal y Penitenciaria: organ of diffusion of a modern

bureaucracy (1936-1946)

La Revista Penal y Penitenciaria : organe de diffusion d'une bureaucratie moderne (1936-1946))

Jeremías Silva

\section{NOTA DEL EDITOR}

Recibido: 23 de enero de 2019 / Aceptado: 05 de mayo de 2019

\section{Introducción}

En 1941 asumió la Dirección General de Institutos Penales (DGIP) el abogado Eduardo Ortiz. Tercer director de la agencia conformada en 1933 con el fin de administrar las cárceles nacionales, la Memoria anual elevada al Congreso Nacional presentaba un balance de los principales logros durante su primer año de gestión. Junto a la información de las diferentes cárceles a su cargo, las estadísticas que daban cuenta del movimiento de presos y la ponderación de las acciones llevadas a cabo, dedicaba una sección a la política de publicaciones de la repartición que dirigía. Allí destacaba que:

La «Revista Penal y Penitenciaria», órgano de la Dirección General, continúa sirviendo al propósito de ser medio de divulgación de normas legislativas, resoluciones del Poder Ejecutivo y de esta Dirección General, en lo que concierne directamente o en forma mediata, al Derecho Penal en todos sus aspectos. Como publicación científica, doctrinaria y práctica, sus páginas contienen artículos originales, fallos judiciales, comentarios de jurisprudencia, análisis de libros y 
revistas, etc. Su importancia y el valor de su contenido, siempre actualizado, la expresa en el hecho de frecuentes pedidos de remisión de la «Revista» formulados por los más distintos Tribunales de nuestro país, y por especialistas argentinos y extranjeros ${ }^{1}$.

2 En efecto, la edición de la Revista Penal y Penitenciaria (RPP) creada en 1936, merecía destacarse entre las innovaciones que llevaron a cabo los funcionarios encargados de los establecimientos penitenciarios nacionales. Destinada a funcionarios y expertos abocados a la situación carcelaria, esta publicación había ganado en pocos años prestigio por contener en sus páginas investigaciones originales, proyectos y legislación -provincial, nacional e internacional en materia penitenciaria-, información sobre congresos científicos, fallos judiciales e información sobre la obra de la DGIP. Instrumento eficaz para difundir el dinamismo y fecundidad de las discusiones, debates y concreciones realizadas en el país y en el extranjero, no es casual que la RPP, el "órgano oficial de la Dirección General de Institutos Penales", ocupe un lugar destacado entre las numerosas políticas acaecidas en materia penitenciaria de la década de 1930. Estas transformaciones deben enmarcarse en la sanción, en 1933 de la ley 11.833 de "Organización carcelaria y régimen de la pena". La normativa discutida y aprobada por el Parlamento Nacional estableció la organización de la DGIP, coronando múltiples esfuerzos previos en pos de centralizar la administración de las prisiones. De esta forma, una vez concretada, esta agencia centralizó la administración de las cárceles de jurisdicción nacional, permitió el encumbramiento de abogados especializados en cuestiones penitenciarias con amplia trayectoria dentro del Estado, y se propuso modernizar las prisiones bajo su dependencia motorizando múltiples iniciativas en su área.

Como expresa la cita con la que iniciamos este trabajo, la RPP era motivo de congratulación para los funcionarios de la DGIP. Justamente, la relevancia que tuvo la revista radicó en la función que cumplió para sus impulsores, y que los trascendió permitiéndole perdurar hasta la década del 80 y ser una referencia ineludible tanto para los expertos como para la burocracia carcelaria por más de 50 años. A pesar de los múltiples avatares que marcaron el derrotero de las políticas penitenciarias en gran parte del siglo XX, la RPP mantuvo su espíritu y estructura desde su primer número aparecido en 1936. Por eso, en este trabajo analizamos la revista desde su fundación hasta el advenimiento del peronismo. Esta periodización coincide con la gestión de los tres primeros directores de la DGIP: Juan José O'Connor (1933-1937), José María Paz Anchorena (1937-1941) y Eduardo Ortiz (1941-1946). Asimismo, 1946 marcó el comienzo de una nueva etapa con el ascenso del peronismo al poder, bajo la dirección de Roberto Pettinato (1947-1955) que, como las políticas penitenciarias de esa época, la RPP adquirió otro perfil ${ }^{2}$.

4 Al examinar la RPP en sus primeros diez años de vida, este trabajo aspira a dialogar con el creciente interés en la historia del Estado, sus agentes, saberes y difusión de las políticas públicas. Estas investigaciones han contribuido a poner de relevancia la centralidad de las revistas oficiales de diferentes organismos estatales. Por cierto, éstas constituyen fuentes documentales imprescindibles para aproximarse al estudio de las instituciones y sus protagonistas. A la vez, y en cierta medida debido a la influencia de las perspectivas de la historia socio-cultural, ellas han sido valoradas como instrumentos claves a la hora de comunicar las medidas de gobierno, fuentes que, en verdad, deben tomarse como objeto de estudio en sí mismo. Muy especialmente, merecieron atención como puntos de mira privilegiados para explorar la relación entre las burocracias, la política y en cierta medida la sociedad ${ }^{3}$. Respecto del caso específico de las revistas de agencias dedicadas a la 
atención del sistema penitenciario poco se sabe sobre su constitución y funcionamiento en América Latina. Recientemente, algunas investigaciones han llamado la atención sobre el vacío historiográfico que existe sobre este tema y señalado la importancia que tienen estas revistas para estudiar diversas problemáticas carcelarias, comprender las formas en que ayudaron a visibilizar socialmente la cuestión penitenciaria e inclusive para demostrar la relevancia política que tuvieron en el encumbramiento de diferentes funcionarios ${ }^{4}$. Como se mencionara, esto exige una perspectiva de análisis que sea sensible tanto a la historia social del estado como a las herramientas de la historia cultural.

5 En las páginas que siguen, procuraremos demostrar como la RPP cumplió un rol central para los funcionarios. Al ser la principal herramienta de difusión de la agencia encargada de las políticas penitenciarias de los gobiernos conservadores su análisis resulta indispensable por dos cuestiones. Por un lado, ilumina las concepciones, ideas y saberes que compartían y consideraban relevante difundir los principales encargados de la DGIP $\mathrm{y}$, por otro lado, al estar destinada fundamentalmente a los funcionarios que gestionaban las prisiones, permite comprender los atributos que debían poseer los cuadros menores de la administración del castigo. Por eso, argumentaremos que la revista tuvo un rol pedagógico, y al mismo tiempo se propuso jugar un papel destacado la conformación de una burocracia moderna, en tanto buscaba que los funcionarios a los que estaba destinada estuviesen informados sobre la obra de gobierno, las medidas implementadas tanto a nivel nacional como provincial, los debates e investigaciones de los expertos dedicados a la cuestión criminal, los principales eventos científicos regionales e internacionales, así como las transformaciones legales y legislativas en materia penal y penitenciaria.

6 Así planteado, este artículo se dividirá en tres secciones: en el primer apartado sintetizaremos las principales características de la reforma penitenciaria de los gobiernos conservadores, y de los directores que la impulsaron, para entender el contexto en que se constituyó la RPP y los objetivos que explicitó; en segundo lugar, nos detendremos en la propuesta de la revista de conjugar los saberes expertos y experiencias que desarrollaban agencias similares en el país y en el extranjero permitiendo reconstruir el clima de ideas y algunas características del rol pedagógico que tenía para los funcionarios; y por último, exploraremos de qué manera la revista se convirtió en el canal predilecto utilizado por los directores para difundir el dinamismo de la obra de gobierno entre la burocracia y los especialistas.

\section{La Revista Penal y Penitenciaria en el marco de la reforma penitenciaria de los años 30}

7 El 30 de septiembre de 1933 el proyecto de ley sobre "Organización carcelaria y régimen de la pena” fue aprobado en el Congreso Nacional de Argentina ${ }^{5}$. La Ley N ${ }^{\circ} 11.833$ instauró y organizó la Dirección General de Institutos Penales, agencia que llevó adelante una intensa actividad proyectando y materializando las políticas penitenciarias del período. Esta normativa, entonces, marcó la coronación de múltiples debates y proyectos legislativos previos ${ }^{6}$, y al mismo tiempo el punto de partida de una reorganización administrativa del sistema penitenciario que la gestión conservadora completaría con otro conjunto de medidas ${ }^{7}$. La organización de los establecimientos penales que instauró la ley comprendía a los establecimientos ubicados en la Capital Federal (Penitenciaría Nacional, Cárcel de Encausados y Asilo Correccional de mujeres), como a los que se 
encontraban en los Territorios Nacionales ${ }^{8}$. Como ya se ha señalado, la creación de la DGIP dentro del Ministerio de Justicia e Instrucción Pública (MJIP) no modificó la concepción de la pena que venía forjándose desde finales del siglo XIX: un régimen de instrucción, trabajo y disciplina9 ${ }^{9}$. El énfasis de los funcionarios estuvo concentrado en garantizar la reeducación del penado y la consiguiente reinserción social. Con este fin, los funcionarios consideraban que la primera cuestión a tener en cuenta debía ser garantizar un régimen de educación moral e instrucción práctica para los presos que no se llevaba a cabo en todos los establecimientos; la segunda medida que se debía implementar concernía al régimen de aprendizaje técnico de un oficio y ganar experiencia laboral, con el fin de contribuir a reintegrase a la sociedad una vez obtenida la libertad (diferenciando la inserción laboral rural o urbana); por último, el régimen disciplinario debía readaptar e inculcar hábitos de disciplina y orden, para "desenvolver la personalidad social del condenado"10. Educación, trabajo, disciplina y orden fueron los pilares que garantizarían el éxito de las instituciones carcelarias argentinas, aunque no siempre se pudieron llevar a la práctica.

8 Sus tres primeros directores compartieron estas premisas. Quizás haya influido su formación profesional y experiencia laboral. Justamente, los tres compartieron un perfil común: Juan José O'Connor -entre 1933 y 1937-, José María Paz Anchorena -entre 1937 y 1941- y Eduardo Ortiz -entre 1941 y 1946- era abogados recibidos de la Facultad de Derecho de la Universidad de Buenos Aires y fueron funcionarios con una extensa trayectoria en las agencias estatales e iniciaron su desempeño en puestos menores de la administración. Juan José O'Connor se recibió de abogado en 1915 e inició su carrera ingresando en el Ministerio de Justicia e Instrucción Pública como empleado de la Inspección General de Justicia en 1922. Por esos años su cargo de inspector lo llevó a supervisar las cárceles de los Territorios Nacionales, lo que le brindó experiencia y lo convirtió en un verdadero especialista en cuestiones penitenciarias. Tras visitar dichos establecimientos carcelarios, J. J. O'Connor elaboraba informes sobre éstos e insistía en expresar su preocupación -compartida con diferentes intelectuales y profesionales de la época- sobre la necesidad de erigir nuevas instituciones carcelarias. En el intento por llevar a cabo sus ideas presentó, en más de una oportunidad, proyectos de nuevos establecimientos, como el que propuso en 1925: una obra de 5 cárceles en los Territorios Nacionales, para las cuales no obtuvo apoyo político. La creación en 1924 de la "Comisión de Superintendencia de Cárceles y Establecimientos de Corrección Nacionales" le permitió un ascenso importante dentro de la administración estatal. Integró esta nueva repartición encargada del sistema carcelario nacional como vocal ${ }^{11}$. Una vez sancionada la ley que constituyó la DGIP y se lo designó para ocupar la dirección, O'Connor implementó importantes obras. Entre las prioridades de su gestión estuvieron la de dotar al país de un sistema penitenciario moderno: esto significaba mejorar la situación de las cárceles de los Territorios Nacionales, la construcción de nuevos edificios, la incorporación de talleres y escuelas, así como solucionar las condiciones de higiene. Ejerció la dirección hasta el 10 de abril de 1937, fecha en que fue designado Juez en lo Correccional de la Capital Federal ${ }^{12}$ . Su sucesor, el Dr. José María Paz Anchorena, fue nombrado prácticamente a las pocas semanas en mayo de 1937, convirtiéndose en el segundo director de la institución. Se recibió de abogado en 1917 con la tesis "La prevención de la delincuencia", distinguida con Diploma de Honor ${ }^{13}$. Rápidamente se destacó por su actuación como representante oficial en ámbitos internacionales especializados, como lo hizo en el IX Congreso Penitenciario Internacional de Londres en 1925. Se desempeñó como consejero titular de 
la Facultad de Derecho a partir de 1931 y profesor extraordinario de Derecho Penal entre 1937 y 1945. Integró al Consejo Asesor de la DGIP y ocupó la dirección de esta agencia entre 1937 y 1941 cuando pasó a desempeñarse como Secretario de la Presidencia de la Nación bajo los gobiernos de Roberto Ortiz y Ramón Castillo ${ }^{14}$. El último, Eduardo Ortiz también se recibió de abogado en la Facultad de Derecho y Ciencias Sociales de la UBA en 1920 presentando su tesis sobre "El estatuto legal y reglamentario de la función pública". Al año siguiente ocupó el cargo de Procurador Fiscal ante el Juzgado Letrado de los Territorios Nacionales de Santa Cruz y Tierra del Fuego. En noviembre de 1923 fue promovido a Juez Letrado del Territorio de Neuquén hasta 1933, momento en que fue designado como Inspector de Justicia del MJIP. Ingresó a la DGIP en 1936 como Inspector General de esta repartición ${ }^{15}$. Desde octubre de 1937 se convirtió en el primer Subdirector General ${ }^{16} \mathrm{y}$ vocal del Consejo Asesor de la DGIP. Al renunciar Paz Anchorena asumió en marzo de 1941 como Director General interino, hasta que el Poder Ejecutivo lo ratificó en su cargo en $1943^{17}$. En diciembre de 1946 renunció a su puesto para desempeñarse como Juez del Crimen de la Capital.

9 Como podemos observar, los primeros directores de la DGIP tuvieron un perfil profesional similar, abogados formados en la UBA, y una vasta experiencia estatal en materia penitenciaria. No es casual que las medidas y orientaciones de la DGIP se mantuviese durante las tres gestiones. Uno de los elementos que concitó la atención de las autoridades desde el principio consistió en dotar a esta agencia de los elementos técnicos, financieros y materiales necesarios para mejorar las prisiones en un contexto atravesado por la crisis económica. Precisamente, durante los dos primeros años de funcionamiento la DGIP administraba únicamente los establecimientos carcelarios de los Territorios Nacionales. Esta situación cambió en 1935, cuando pasaron a su órbita las dependencias ubicadas en la Capital Federal, que antes dependían de la Dirección de Justicia del MJIP. Sin dudas, esta transformación podía ser concebida como una ampliación de las esferas de acción, todo un logro para la DGIP. Sin embargo, como podemos observar en la Memoria ministerial que elaboró esta repartición sobre sus actividades del año 1935, y que se reproducía en el primer número de la RPP, modificaba completamente su estructura al ampliar el número de personal y de presos que quedaban bajo su autoridad. Así lo documentaba y hacía saber O'Connor: hasta septiembre de 1935 dependían de la DGIP quinientos cincuenta y dos empleados, a partir de esa fecha pasaron a ser mil setecientos ochenta y uno. Por eso, al referirse a la situación del personal que estaba a su cargo señalaba que:

Si pretendemos abandonar el empirismo de nuestra política penitenciaria y pasar a nuevas orientaciones dentro de un orden técnico, lo esencial y primordial es contar con un personal capacitado, compenetrado de la obra y dispuesto a aportar una colaboración fuera de toda medida burocrática. El personal de la Dirección General, entidad directiva, no puede ir a aprender a una cárcel, sino que debe ir a enseñar.

10 La Dirección General es, o por lo menos debe ser, un organismo técnico; y su personal, de probada capacidad técnica, ya por haberse destacado en estudios de la materia o por la experiencia adquirida en la práctica de la vida de las cárceles.

11 Dentro de ese orden no podemos decir que contamos hoy con tales colaboradores, lo que implica reconocer que la eficiencia de la Dirección en tales condiciones queda resentida. (...) No importa lo dicho empequeñecer o restar méritos a nadie, sino que tiene a establecer una verdad inconcusa. La Dirección General tendrá que ser una especie de estado mayor, al cual sólo llegan los más capaces, y los más preparados en materia penal y penitenciaria. 
12 Dicho lo anterior, será suficiente con extender el panorama, para comprobar que los mismos principios, aunque suavizados, habrán de regir en un futuro la organización de las cárceles ${ }^{18}$.

J. J. O'Connor concebía a la DGIP como una agencia técnica y subrayaba la necesidad de poseer un personal capacitado y con experiencia en la gestión carcelaria. La centralización implicaba contar con funcionarios capaces de diseñar proyectos, implementar medidas tendientes a mejorar las prácticas de castigo y acortar la distancia que mediaba entre las cárceles modelos (la Penitenciaría Nacional y la Cárcel de Ushuaia) y las ubicadas en los Territorios Nacionales, que en las primeras décadas del siglo XX carecían de presupuestos, infraestructura y personal adecuado ${ }^{19}$. Y cobra mayor sentido al constatar que el personal a cargo de la DGIP creció sustantivamente durante las décadas del treinta y cuarenta, alcanzando al comienzo de la gestión peronista el número de dos mil quinientos noventa y siete personas ${ }^{20}$. Es por esto, que resulta revelador que para el primer director de la DGIP los funcionarios ocuparan una preocupación y sea motivo de reflexión, en tanto constituían engranajes fundamentales en pos de transformar la realidad penitenciaria nacional.

Es justamente en este contexto que surge la RPP, el "Órgano de la Dirección General de Institutos Penales”. Al sancionarse el Reglamento Orgánico de la DGIP, el segundo artículo definía las atribuciones del Consejo Asesor, entre las que se destacaba: "Propender a la difusión y conocimiento de nuestro régimen penal, de las conclusiones de congresos o conferencias nacionales o extranjeras; estableciendo con ese objeto un servicio de información y evacuando las consultas sobre la materia que formulen autoridades de la Nación o de las Provincias"21. Podría afirmarse que esta revista expresó un aspecto constitutivo y singular de la expansión de las capacidades de los Estados nacionales durante las primeras décadas del siglo XX, justamente porque evidenciaron el impulso recibido por los instrumentos de difusión y comunicación, crecientemente masivos, dirigidos a diferentes públicos ${ }^{22}$. El desarrollo de sociedades de masas, con poblaciones cada vez más alfabetizadas, la aparición y creciente disponibilidad de nuevos medios de comunicación -del que la multiplicación de diarios y revistas era la prueba más evidente-, transformaron los modos de comunicación de los funcionarios ${ }^{23}$. Si ya desde mediados del siglo XIX, los Estados debieron crear naciones, a comienzos del siglo XX, las contiendas bélicas, las innovaciones técnicas, las crisis económicas, la ampliación del sufragio y la competencia electoral, condujeron a las burocracias a apelar a nuevas formas de comunicación ${ }^{24}$.

De esta manera, la revista buscaba ser una herramienta útil para los especialistas, pero sobre todo para los funcionarios, llenando un vacío en el campo penal y penitenciario. Y puede afirmarse, también, que el crecimiento de la burocracia estatal en el sistema carcelario también habría generado un público, que aunque no necesariamente contara con una formación profesional y pudiera ser considerado experto, comenzara a interesarse por estar informado de estas cuestiones ${ }^{25}$. En otras palabras, la revista podía interpelar a los especialistas y también a aquellos que sin ser expertos formaron parte de la burocracia estatal del sistema penitenciario. En tal sentido, puede que estas revistas cumplieran también una misión pedagógica, instructiva y lo que no era menos importante contribuyeran a crear un sentido de identidad más inclusivo entre expertos y funcionarios menores. Merece enfatizarse también que no sólo esta revista se proponía reproducir información, cumplía para la burocracia carcelaria diversos objetivos: informar, reunir noticias diversas, ofrecer investigaciones novedosas que se estaban 
produciendo, y al mismo tiempo intervenir en los debates sobre la acuciante cuestión criminal que era uno de los problemas que concitaban la atención del Congreso Nacional y el gobierno, restablecida las instituciones democráticas y elecciones en 1932. En tal sentido, la revista expresaba la necesidad que tenía esta burocracia de terciar con una voz propia en el dialogo que en las diversas instituciones del Estado estaba teniendo lugar en materia penitenciaria.

De esta forma, dentro del conjunto de medidas desarrolladas por la administración del castigo de los gobiernos conservadores, la constitución de la RPP ocupó un lugar privilegiado al ser la única publicación oficial que contenía información de especialistas (criminólogos, penitenciaristas, abogados, médicos legalistas, funcionarios) sobre cuestiones carcelarias, así como de los funcionarios encargados de la gestión gubernamental. No es casual que un año antes finalizase la publicación de la Revista de Criminología, Psiquiatría y Medicina Legal, prestigiosa publicación que, desde principios de siglos, se constituyó como un ámbito de discusión sobre delincuencia, prisiones y justicia ${ }^{26}$. Por eso, como destaca su primer número, la publicación de la revista perseguía

...un doble objeto: en primer término, vincular entre sí a todos los organismos de defensa social que depende de la Dirección y del Consejo Asesor, haciendo conocer los proyectos, reglamentaciones, dictámenes y obras, que ellos elaboren y realicen. En segundo término, aspira a ser tribuna donde se expongan y se estudien los problemas penales y penitenciarios ${ }^{27}$.

17 La RPP constituyó un instrumento primordial en la difusión de ideas y de acciones en materia penitenciaria llevadas adelante por la burocracia carcelaria. Desde su nacimiento la revista se propuso convertirse en una referencia obligada para los funcionarios y para el público especializado. La edición conjunta de trabajos monográficos, información oficial y jurisprudencia permitió discutir y reflexionar a los expertos sobre saberes científicos y técnicos, al mismo tiempo que facilitó los contactos entre los académicos y los funcionarios, quienes no descuidaron informar sobre la agenda estatal en política penitenciaria y sobre los resultados obtenidos. Por ello, agregaba en la presentación realizada en el primer número que "sus páginas están abiertas" a todos los que tengan preocupación por la reforma de los delincuentes, "lo cual significa que pueden escribir en ellas tanto los maestros universitarios y los altos funcionarios técnicos de la especialidad, como los observadores inteligentes del personal de nuestras cárceles" 28 . Esta alusión al personal de las prisiones no parece casual. La RPP los convocaba a enviar contribuciones que den cuenta de sus experiencias en los establecimientos carcelarios.

Editada trimestralmente, la RPP contenía quinientas páginas anuales aproximadamente. El Consejo Asesor de la DGIP era responsable de la RPP. Dicho consejo estaba presidido, según la ley 11.833, por el Director General -Juan José O'Connor-, e integrado por cuatro vocales: un profesor de Derecho Penal de la Facultad de Derecho -José María Paz Anchorena-, el Presidente del Patronato de Liberados y Excarcelados -Jorge Frías-, el Director del Anexo Psiquiátrico -Osvaldo Loudet-, y Jefe del Registro Nacional de Reincidencia -Víctor Paulicci Cornejo-. La impresión de esta publicación se llevó a cabo en los Talleres Gráficos de la Penitenciaría Nacional, como todas las obras de difusión impresa de la DGIP. Este aspecto no es menor, las diferentes gestiones contaban con una moderna imprenta ubicada en el principal establecimiento carcelario y sede de la DGIP, lo que le permitía disponer de los elementos necesarios para la puesta en práctica de los proyectos editoriales ambiciosos, como la RPP, a bajo costo. Como veremos a continuación, la revista pudo distinguirse, en primer lugar, por constituir un espacio para la difusión de saberes sobre la cuestión criminal. 


\section{Tribuna de los saberes sobre cuestión criminal: experiencias provinciales, regionales e internacionales} contenidos se ordenaron en apartados temáticos. La publicación comenzaba con la presentación de trabajos originales que incluían artículos y colaboraciones de especialistas nacionales y extranjeros: médicos criminólogos, psiquiatras, abogados, policías, funcionarios, jueces. Esta sección, que era la única carente de un título introductorio, buscaba compartir investigaciones, opiniones y experiencias de los expertos dedicados a estudiar las cuestiones penitenciarias, aunque también ocupaban un espacio menor las temáticas penales, policiales y jurídicas. Es en esta sección donde puede observarse, sin duda, la impronta científica de la revista y la aspiración de servir como canal de difusión de las producciones de aquellos dedicados a la cuestión criminal ${ }^{29}$. En Argentina, existía una tradición de revistas científicas dedicadas a estos problemas, entre las que podemos mencionar junto a la reconocida Revista de Criminología, Psiquiatría y Medicina Legal, la Revista Penitenciaria dirigida por José Luis Duffy (Director de la Cárcel de Encausados) entre 1905 y 1910.

esta manera, los lectores podían hallar en las páginas de la RPP la justificación de proyecto de un código de Faltas de la Provincia de Santa Fe elaborado por el prestigioso jurista Sebastián Soler ${ }^{30}$, el informe elaborado por reconocidos expertos sobre la situación de los establecimientos carcelarios de la Provincia de Buenos Aires ${ }^{31}$, consideraciones sobre la emoción violenta en el Código Penal escrito por el médico Benjamín Spota ${ }^{32}$, la recopilación de experiencias y propuesta para editar un periódico para los reclusos realizada por Paz Anchorena ${ }^{33}$, las impresiones recogidas sobre el sistema penitenciario francés del abogado Juan Silva Riestra en su viaje de estudios ${ }^{34}$, el proyecto y los fundamentos de la relevancia política de conformar una Comisión Especial de Legislación Carcelaria en el parlamento ${ }^{35}$, o las actividades realizadas por el Patronato de Liberados ${ }^{36}$. Esta sección no contó con una cantidad regular de artículos. Algunos números contenían un solo trabajo, y en otros podían encontrarse hasta cinco contribuciones. En ciertas ocasiones reproducían semblanzas de figuras históricas renombradas del penitenciarismo internacional. Con un claro objetivo divulgativo, los lectores podían encontrar las reflexiones de la renombrada penitenciarista española del siglo XIX Concepción Arenal, un recordatorio sobre la obra del reformista inglés John Howard al cumplirse el centenario de su muerte, palabras alusivas al cumplirse diez años del fallecimiento del destacado jurista italiano Enrique Ferri, o un homenaje al Ingeniero Catello Muratgia por su obra en la Cárcel de Ushuaia ${ }^{37}$.

21 A la par de difundir los estudios de las "ciencias penitenciarias", la RPP brindaba espacio para la publicación de informes y trabajos originales de la propia burocracia penitenciaria tal como lo declaraba en su primer ejemplar. $\mathrm{E} l$ tercer número, contaba con un trabajo firmado por Mariano De Yuliis, cuya pertenencia institucional rezaba "De la Dirección General de Institutos Penales", y presentaba los resultados del estudio realizados sobre el régimen alimenticio en las cárceles de los Territorios Nacionales a los que calificaba de "inadecuado"38. Por ello, proponía una nueva dieta para los penados basadas en "los conocimientos modernos de la alimentación racional". De igual modo, Pedro Escudero exhibía las conclusiones de su investigación sobre la misma temática, la alimentación de los presos en las cárceles de los Territorios Nacionales ${ }^{39} \mathrm{y}$ el Inspector de Escuelas de

Revista Historia y Justicia, 12 | 2019 
Cárceles, Ernesto Grassi, proponía un plan educativo basado en principios morales y religiosos para los presos ${ }^{40}$. Podemos considerar que estas cuestiones preocupaban a las autoridades, por eso se encargaron sendos estudios a funcionarios de la DGIP que su revista divulgaba.

Asimismo, en numerosas oportunidades la revista dedicaba espacio a información institucional relevante. Los cambios en la dirección de la agencia ocuparon un lugar preponderante en las páginas de la RPP. Los detalles sobre las nuevas autoridades de la Dirección o del Ministerio de Justicia eran cubiertas con notas alusivas ${ }^{41}$. Cuando se realizó la designación de J. M. Paz Anchorena o de E. Ortiz se presentaron las credenciales y antecedentes de los flamantes directores. Allí los lectores podían encontrar las referencias sobre su formación, experiencia profesional y la actividad relacionada con las cuestiones penitenciarias ${ }^{42}$. Asimismo, al renunciar O'Connor, la revista reprodujo los homenajes que le realizó el personal de la dirección dado el “... aprecio que conquistará el ex Director General entre sus empleados (que) se puso de manifiesto en todos los momentos de su carrera al frente de la repartición que él creara"43. De igual modo, cuando Paz Anchorena fue convocado a desempeñar el cargo de Secretario de la Presidencia de la Nación en 1941, la revista realizó un balance de los logros del director saliente, y añadía que:

Todo era proyectar, trajinar y construir, cuando en 1933, se sancionó la ley de Organización Carcelaria y Régimen de la Pena: Comenzaba a transformarse totalmente el sistema penitenciario nacional. Caían barrotes vetustos abriéndose paso a una nueva técnica, índice de una nueva época, precursora de otras construcciones. Desde ese mismo instante, el doctor Paz Anchorena se vinculó a la labor emprendida por la recién creada Dirección Genera ${ }^{14}$.

Para destacar los méritos de Paz Anchorena, los funcionarios ponían en valor las concreciones de su gestión y su compromiso desde los orígenes de la DGIP. Al mismo tiempo puede observarse como en la nota la sanción de la ley 11.833 constituía un momento fundacional que inauguró una nueva época para el sistema penitenciario nacional. Así, tempranamente comenzaba a originarse la conformación de una memoria institucional que ubicaba a 1933 como un parteaguas en la historia de la prisión en Argentina, que perdurará hasta la actualidad ${ }^{45}$.

Por último, la revista dedicaba varias secciones a presentar la información referente a eventos, proyectos y legislación internacional. Un lugar preferente lo ocuparon los congresos científicos organizados en aquellos años. Estas secciones revelan la preocupación de las autoridades de la DGIP por estar al tanto de las experiencias y debates que se llevaban a cabo en el extranjero. Como los estudios sobre el Estado han puesto de manifiesto en los últimos años, las agencias gubernamentales y funcionarios apelaron, se nutrieron y participaron de discusiones transnacionales ${ }^{46}$. Las propuestas o concreciones que se desarrollaban en otras naciones inspiraron modelos de acción, se referenciaban a la hora de elaborar proyectos propios o servían para legitimar la implementación de políticas públicas ${ }^{47}$.

De este modo, el espacio que dedicó la RPP a los desarrollos extranjeros ilumina la intensa actividad desplegada durante los años '30 por los Estados y organizaciones internacionales. Una de las más importante por aquellos años, la Comisión Internacional Penal y Penitenciaria, fue el centro de varios artículos que referían tanto a su historia, como a las propuestas que realizaba ${ }^{48}$. Por ejemplo, en el segundo número de la RPP traducía y transcribía el documento titulado "Conjunto de reglas para el tratamiento de 
los presos" elaborado en agosto de 1934 y aprobado por la Sociedad de las Naciones, donde se aconsejaba a los países miembros adoptarlo ${ }^{49}$. Además, pueden citarse, a modo de muestra, el Código Penal de la República de Costa Rica ${ }^{50}$, el Reglamento del Instituto de Clasificación y Criminología de la Dirección General de Prisiones de Chile ${ }^{51}$, o el Código Penal brasileño de $1940^{52}$.

La multiplicidad de congresos internacionales dedicados al derecho penal, los sistemas penitenciarios y la criminología positivista tuvieron igualmente una cobertura regular en la revista. Síntesis de los temas discutidos, paneles, debates y, naturalmente, las conclusiones a las que arribaron, documentan la fecundidad de los eventos científicos y expertos durante el periodo de entreguerras ${ }^{53}$. Pero sin dudas, el mayor interés de la revista estuvo en los eventos regionales, destacándose los Congresos Latinoamericanos de Criminología celebrados en 1938 y 1941, en Buenos Aires y Santiago de Chile respectivamente $\mathrm{e}^{54}$. La RPP brindó información detallada y la transcripción de los discursos de apertura, el programa, las conclusiones y las visitas realizadas a los establecimientos que formaron parte del cronograma de actividades oficiales. Acompañaron la cobertura múltiples fotos de los asistentes en diversas actividades documentando la importancia e impacto que tuvieron estos eventos. No resulta casual dado que contaron con una amplia presencia de expertos y funcionarios de Argentina y del continente ${ }^{55}$.

Pero los eventos regionales constituyeron sólo una parte de los fecundos intercambios y canales de diálogo entre los funcionarios del Cono Sur. Las visitas y viajes oficiales ${ }^{56}$, junto a informes o proyectos que se discutían tanto en Uruguay como en Chile pueden encontrarse con periodicidad ${ }^{57}$. Justamente, una parte importante de la publicación estuvo destinada al estudio de la legislación y los proyectos legislativos elaborados por funcionarios de diferentes países. Estas eran: Legislación Nacional, Legislación Penal, Legislación Extranjera y Técnica Penitenciaria. Estas secciones reproducían reglamentos de diferentes establecimientos, patronatos, cárceles femeninas, códigos penales aprobados y debatidos en distintos países, leyes que atendían a problemas de la administración del castigo, delitos políticos, delincuencia infantil, libertad condicional o justicia criminal. La selección de casos era amplia y variada exponiendo en primer lugar, la situación y avances nacionales. No es casual que el primer número reproduzca el Mensaje dirigido por el presidente Agustín P. Justo al Congreso Nacional el 15 de septiembre de 1933 que acompañó el proyecto de ley que, tras breves intervenciones en ambas cámaras, terminó sancionándose a las dos semanas y promulgándose el 9 de octubre de ese mismo año como la Ley $11.833^{58}$.

Como señalamos, entre la abundante información sobre las transformaciones legales e institucionales ocurridas en el exterior, sobresalían las experiencias de los países latinoamericanos. Es importante remarcar estos datos porque a lo largo del periodo que analizamos los funcionarios gubernamentales mantuvieron un importante interés en conocer las expresiones legislativas de otros países del mundo a fin de poder recabar experiencias que podían ser útiles para aplicar o tener en cuenta a nivel local; en segundo lugar, este interés no se concentró en dirigir la mirada exclusivamente en lo que sucedía con estos temas en Estados Unidos o Europa occidental como puede encontrarse en las publicaciones de los criminología positivista de fines de siglo XIX ${ }^{59}$, sino que se puede observar una búsqueda y referencia a información mucho más amplia y heterogénea a diferencia de lo que sucedía en el pasado, en especial las experiencias de la región. Como 
veremos a continuación, la impronta más académica, científica y atenta a las transformaciones internacionales se conjugaron con otras aspiraciones y objetivos

\section{Comunicar la obra de gobierno: proyectos, políticas y normativa}

Junto a la divulgación de investigaciones originales y la publicación de legislación, proyectos y experiencias extranjeras, la RPP se propuso y dedicó gran parte de sus páginas a difundir y publicitar la obra de gobierno en materia carcelaria. Precisamente, las últimas secciones, tituladas "Nuestros establecimientos", "Información Administrativa", "Resoluciones oficiales" y "Panorama Carcelario", brindaban una imagen detallada de las diversas tareas cotidianas de la administración del castigo. Estas secciones, que ocupaban varias páginas, describían las medidas y acciones que se desarrollaban en las instituciones carcelarias a lo largo del país. Un rasgo que merece resaltarse es que la información que se reproducía, en particular la sección "Panorama Carcelario", detallaba las transformaciones en los establecimientos o agencias de gestión provincial. Esto evidencia el fortalecimiento de los canales de comunicación entre las burocracias y autoridades de la agencia nacional y de las provinciales.

Actos, inauguraciones, mejoras de infraestructura, visitas ilustres, las estadísticas anuales del movimiento de penados, medidas que atañían a los presos y a sus familias, al personal de vigilancia y a los administrativos, podían encontrarse en estas secciones. Esta cuestión es sumamente iluminadora por dos razones. En primer lugar, ilustra la importancia que los funcionarios otorgaron a la sistematización y difusión de las medidas. A su turno, esta centralidad iba creando una práctica burocrática que requería reseñar todas aquellas actividades y acciones consideradas prueba de la modernidad de esta agencia: publicitar normativas, contar con fotógrafos (con mayor sistematización desde 1940) y reproducir los discursos de actos o celebraciones. En segundo lugar, el espacio dedicado al racconto de las actividades realizadas en el seno del sistema penitenciario, por sus propios agentes, expresa la visión que los funcionarios procuraban proyectar sobre su gestión, y en última instancia, sus propias representaciones sobre lo que entendían por una agencia moderna. Y en ese conjunto emergían las figuras de los directores. Eran ellos quienes motorizaban políticas y múltiples acciones innovadoras, que incluían proyectos arquitectónicos para trasladar la Penitenciaría Nacional ${ }^{60}$, la celebración de actos conmemorativos por la muerte de tres guardiacárceles en un intento de fuga de la Cárcel de Encausados en octubre de $1933^{61}$, un concierto sinfónico para los penados ${ }^{62}$, la inauguración de un mástil en la Cárcel de Ushuaia ${ }^{63}$, o la apertura de talleres en la Cárcel de Mujeres ${ }^{64}$. 
Plan de traslado de la Penitenciaría Nacional y construcción de dos colonias penales

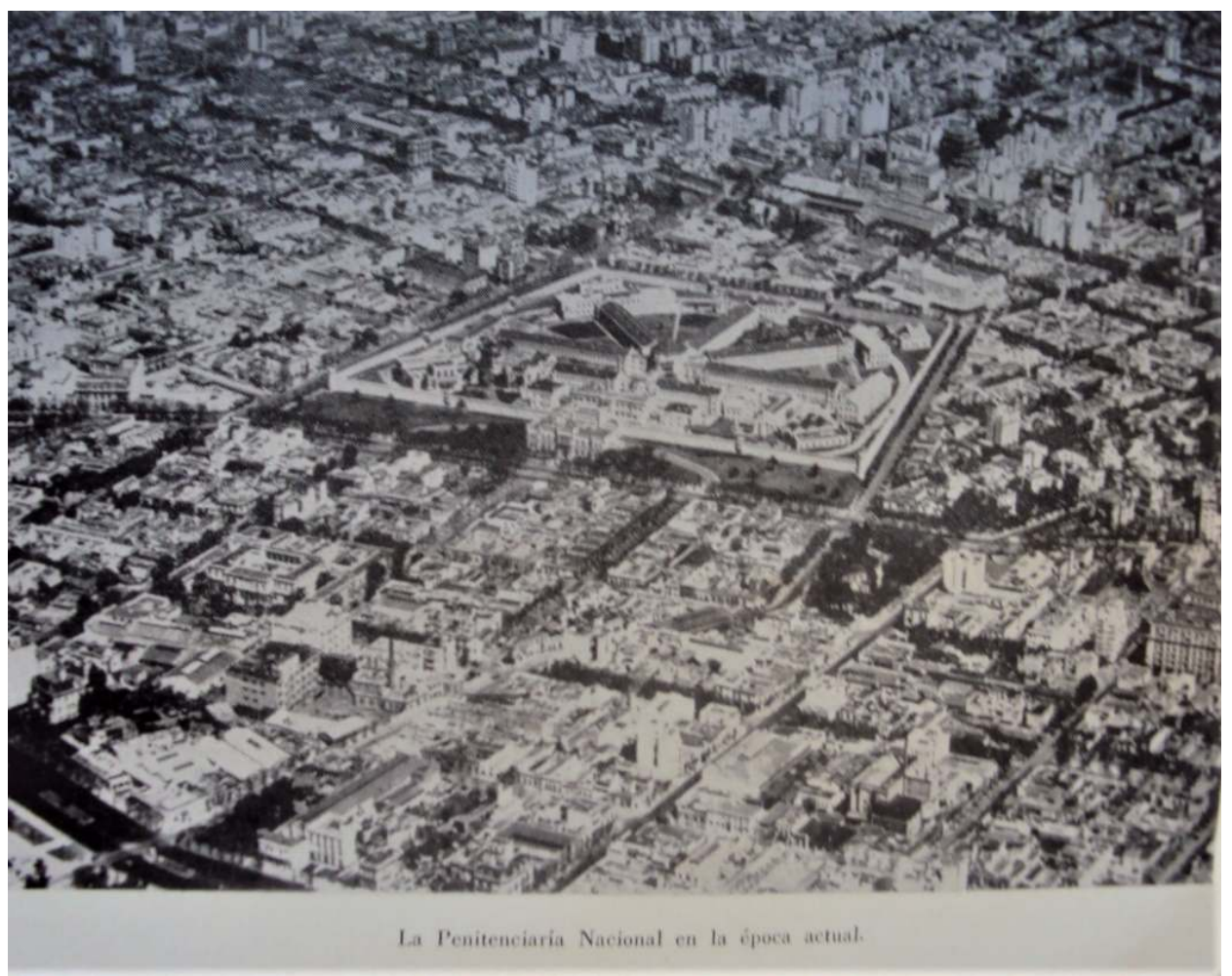

"Plan de traslado de la Penitenciaría Nacional y construcción de dos colonias penales", RPP, año III, n 9, 1938, s/p

31 Asimismo, la RPP informaba sobre la normativa de la Dirección o de aquellos organismos vinculada a ellas, convirtiéndose en una referencia ineludible para los funcionarios que buscaran estar al tanto de las transformaciones reglamentarias o que debían implementar las nuevas medidas. Esta cuestión cobra relevancia en un sistema penitenciario cada vez más complejo y con un personal en constante aumento. Cumplía en este sentido, con el objetivo de uniformar y homogenizar las prácticas de castigo. Las designaciones del personal, los proyectos de nuevas construcciones o inauguraciones de nuevos establecimientos brindaban testimonio de la labor y el dinamismo llevada a cabo por la DGIP. Las múltiples y variadas actividades implicadas en el desarrollo de políticas destinadas a mejorar diversos aspectos de la administración carcelaria expresa la conformación de una burocracia moderna, que, junto a las discusiones internacionales y los congresos científicos, también desarrollaba acciones que mejoraban la calidad de los establecimientos y que juzgaba imprescindible darlos a conocer.

No es menor el lugar que ocupó la abigarrada normativa tendiente a sistematizar y homogeneizar las prácticas de castigo. Las resoluciones se transcribían completas con el fin de difundirlas. Por ejemplo, en 1936 se reglamentaba la realización de los actos o celebraciones en los establecimientos carcelarios y se solicitaba a los directores de las prisiones que debían solicitar autorización con antelación antes de llevar a cabo alguna actividad $^{65}$. De la misma manera, los lectores de la RPP podían hallar la justificación e ítems del nuevo fichero de los penados que debían completarse en todas cárceles, las normas de funcionamiento del nuevo Hospital Penitenciario Central, o el reglamento sobre el peculio correspondiente al trabajo de los presos ${ }^{66}$. 

DGIP al público interesado o experto. Por ejemplo, en el primer número publicaba una nota enviada por O'Connor a los directores de las cárceles de los Territorios Nacionales titulada "Sobre política carcelaria" ${ }^{67}$. Allí, el Director General destacaba la "obra de reforma carcelaria" y no dudaba en afirmar que "De aquellas cárceles de años atrás, que la prensa local y de la Capital Federal, llamaban focos de inmundicia y motivos de vergüenza, a los establecimientos actuales, media un abismo". Sin embargo, a pesar del tono laudatorio convocaba a no darse por satisfechos ni llamarse al engaño. Por eso, instaba a los funcionarios a reforzar los lineamientos en los que debían redoblar los esfuerzos. El primero de ellos concernía al trabajo: "En las cárceles deben trabajar todos los presos", ya que el ocio era un factor que aumentaba la corrupción y no cumplía con el fin de rehabilitar a los penados. Por eso sugería a los directores que pongan en práctica los recursos a su alcance que no implicasen una erogación presupuestaria: trabajar la tierra, enseñanza de carpintería y mecánica rural, así como la mecánica automotriz. Esto posibilitaría que el preso encuentre fácilmente trabajo al salir de la prisión. La segunda cuestión refería a la escuela. Aquí también O'Connor apelaba a las estrategias para garantizar la instrucción, aún en aquellos lugares donde no existían aulas. Y señalaba que sólo un 22 \% de los presos de los Territorios Nacionales recibía instrucción. En el tercer punto reclamaba la presencia diaria de un médico en las prisiones para realizar exámenes, tratar a los enfermos y llevar "una pequeña ficha" de cada penado. Completaban la misiva el pedido a garantizar los servicios religiosos ("manteniendo la libertad de culto"), favorecer el acceso a las modestas bibliotecas y propiciar el ejercicio físico. Sobre esta última cuestión, convocaba a los funcionarios a no descuidar la actividad física pues era un elemento que ayudaban a mitigar "el ya complejo problema sexual en las cárceles". Así pues, uniformar las medidas, llamar a la colaboración de los funcionarios y redoblar los esfuerzos para maximizar la administración de los recursos disponibles presentes en la nota condensan las premisas centrales del proceso de modernización de los años 30 y principios de los 40 . En ocasiones, la falta de presupuesto -o que éste se destinara a la infraestructura carcelaria- suponía alentar la imaginación de los directores de cárceles para mejorar los tratamientos en un contexto económico con lentos signos de recuperación, pero que debían sortear para alcanzar el objetivo de transformar las prácticas de castigo.

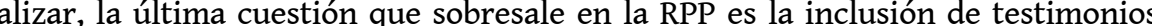
visuales que acompañaron la sección de información sobre los actos, obras en desarrollo o inauguraciones de establecimientos carcelarios. Sin duda, como han sostenido Anahí Ballent y Adrián Gorelik, los funcionarios de los gobiernos conservadores utilizaron la capacidad simbólica y expresiva de la materialidad de la obra pública para resaltar la modernización territorial del país que "a través de imágenes, desplegaba un discurso que hablaba de progreso y de una transformación productiva basada en la técnica" ${ }^{68}$. La administración penitenciaria no fue ajena a la política estatal de los gobiernos conservadores que pretendían integrar físicamente al país, no casualmente durante esta gestión mejoraron la mayor parte de las instituciones penitenciarias y se construyeron nuevos establecimientos en los Territorios Nacionales. Cabe señalar también, que en estos años se promovió el objetivo de consolidar y nacionalizar las fronteras, haciendo efectiva la presencia del Estado en las zonas más alejadas de la sede gubernamental. Fue en este contexto que se definieron los proyectos de renovar o construir cárceles en los Territorios Nacionales. Los funcionarios de la DGIP apuntaron a que la premisa de la modernidad

Revista Historia y Justicia, 12 | 2019 
punitiva alcanzara el interior del país en el plano material y edilicio. De esta forma se intentó saldar una deuda importante de las administraciones anteriores, denunciada históricamente por funcionarios, expertos y legisladores desde principios de siglo.

Adelantan las obras de la nueva cárcel de General Roca

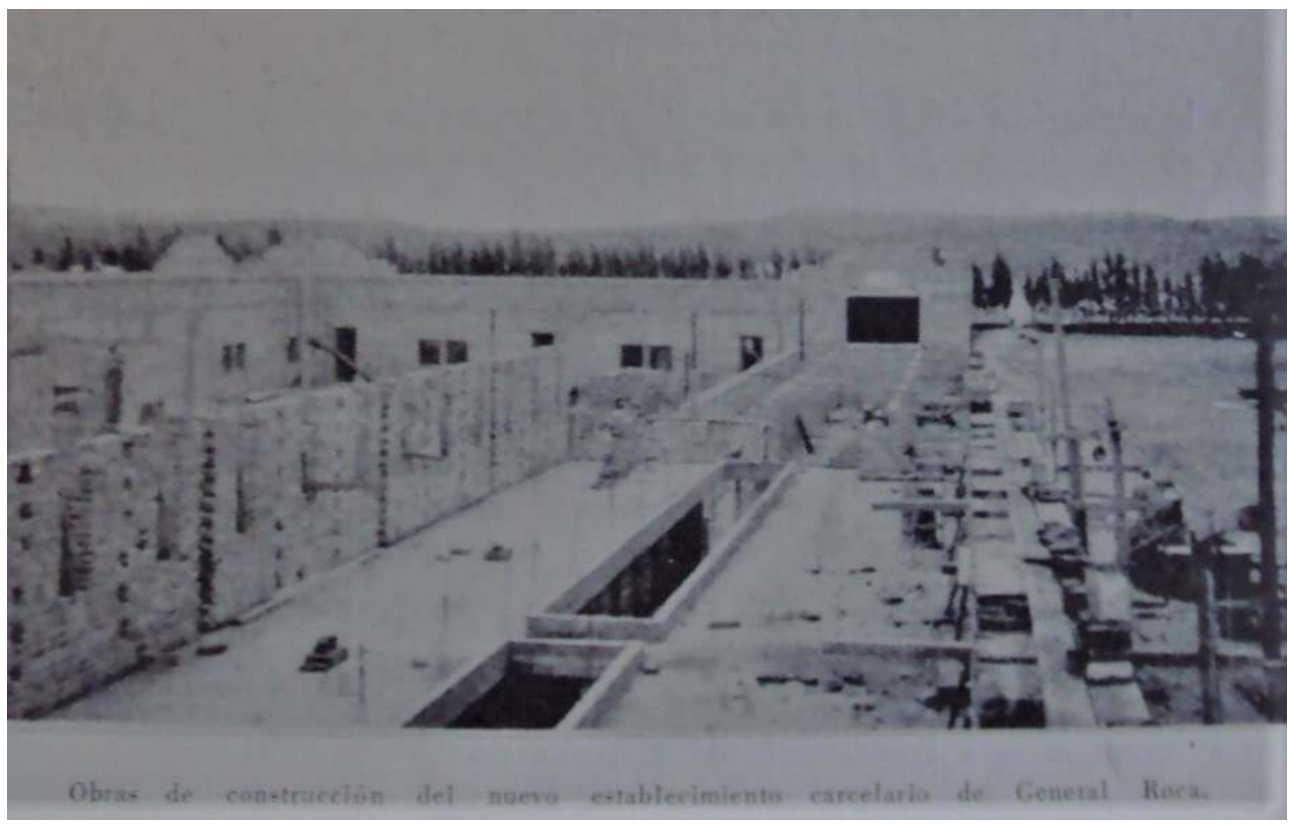

"Adelantan las obras de la nueva cárcel de General Roca", RPP, año III, nº 10, 1938, p. 669.

La DGIP encontró la forma de publicitar los diversos intentos de institucionalización de la administración del castigo en el interior con la creación el 8 de julio de 1940 de la subsección "Fotografías y planos" dependiente de la Oficina Técnica. Con la conformación de esta repartición se pretendió "obtener el reflejo fiel de la labor que se realiza en los establecimientos penales de la Nación, en su mayoría alejados de la Capital Federal, como medio más conveniente para exhibir la marcha de las obras, su estado y las necesidades que sea menester satisfacer"69. Como se ve en la presentación se insiste en la importancia de documentar los avances y progresos de las tareas desarrolladas en materia penitenciaria, en particular, en el interior del país. Claro que, la relevancia que cobró la fotografía para la DGIP no constituía una novedad de los años 30. Desde principios de siglo $\mathrm{XX}$, diferentes agencias estatales incorporaron divisiones de fotografías ${ }^{70}$. Los testimonios visuales, como demostró Verónica Tell, jugaron un papel preponderante en la construcción de relatos de progreso y modernización estatal desde fines de siglo XIX, constituyendo un dispositivo central en el imaginario de un Estado moderno. Las fotografías, según esta autora, permitían simbolizar el progreso gubernamental, a la vez que documentar y validar las acciones de la burocracia ${ }^{71}$. Sin dudas, esta cuestión cobra relevancia en el marco del desarrollo y consolidación de una cultura de masas, como el que atravesaba la sociedad argentina desde las primeras décadas del siglo XX, momento en que la producción y circulación de imágenes se volvieron fenómenos crecientes y cada vez más cotidianos ${ }^{72}$, y que alcanzará en la gestión penitenciaria su punto más relevante durante la dirección de Roberto Pettinato ${ }^{73}$.

Vale aclarar que mientras el recurso fotográfico fue un insumo constante de la RPP desde su nacimiento, otros documentos oficiales como las memorias del Ministerio de Justicia e 
Instrucción Pública mostraron fotografías en sus balances a partir del año 1938. La realización de los balances de actividades anuales y la descripción de los trabajos de cada una de las cárceles se acompañaron con varias imágenes centradas en tres aspectos: los establecimientos penales en proceso de construcción, ya finalizados y obras edilicias relevantes.

Dentro del conjunto, dos ejemplos se destacan. En 1938 se inauguró un Anexo Psiquiátrico en la Penitenciaría Nacional. Bajo la dirección de J. M. Paz Anchorena al frente de la DGIP, se concretó este ansiado proyecto que ya lo establecía la ley 11.833. Sus tareas consistían en formular el diagnóstico psicofisiológico de cada delincuente y se autorizó a tratar a aquellos penados que padecieran psicosis aguda o simple. Este anexo coronaba uno de los proyectos más ansiados de los criminólogos: contar con un espacio para el examen psiquiátrico de los penados en los establecimientos penitenciarios. El anexo contaba con once camas, cuatro celdas de seguridad y una de asilamiento para indisciplinados. También poseía consultorios médicos y una pieza para el enfermero de guardia. En el exterior disponía de un patio con mesas, bancos y jardines destinados al esparcimiento de los enfermos. Su ubicación dentro de la Penitenciaría Nacional estaba cerca del Hospital Penitenciario para poder realizar análisis clínicos, quirúrgicos y de laboratorio ${ }^{74}$. La RPP del año 1938 reprodujo el discurso de apertura ${ }_{20}$ dada la magnitud de la obra también se editó en forma de folleto ${ }^{75}$ 医y publicó diversas fotos del acto de apertura, del local destinado a los cuartos y del jardín.

Inauguración del Anexo Psiquiátrico Central de la Penitenciaría Nacional

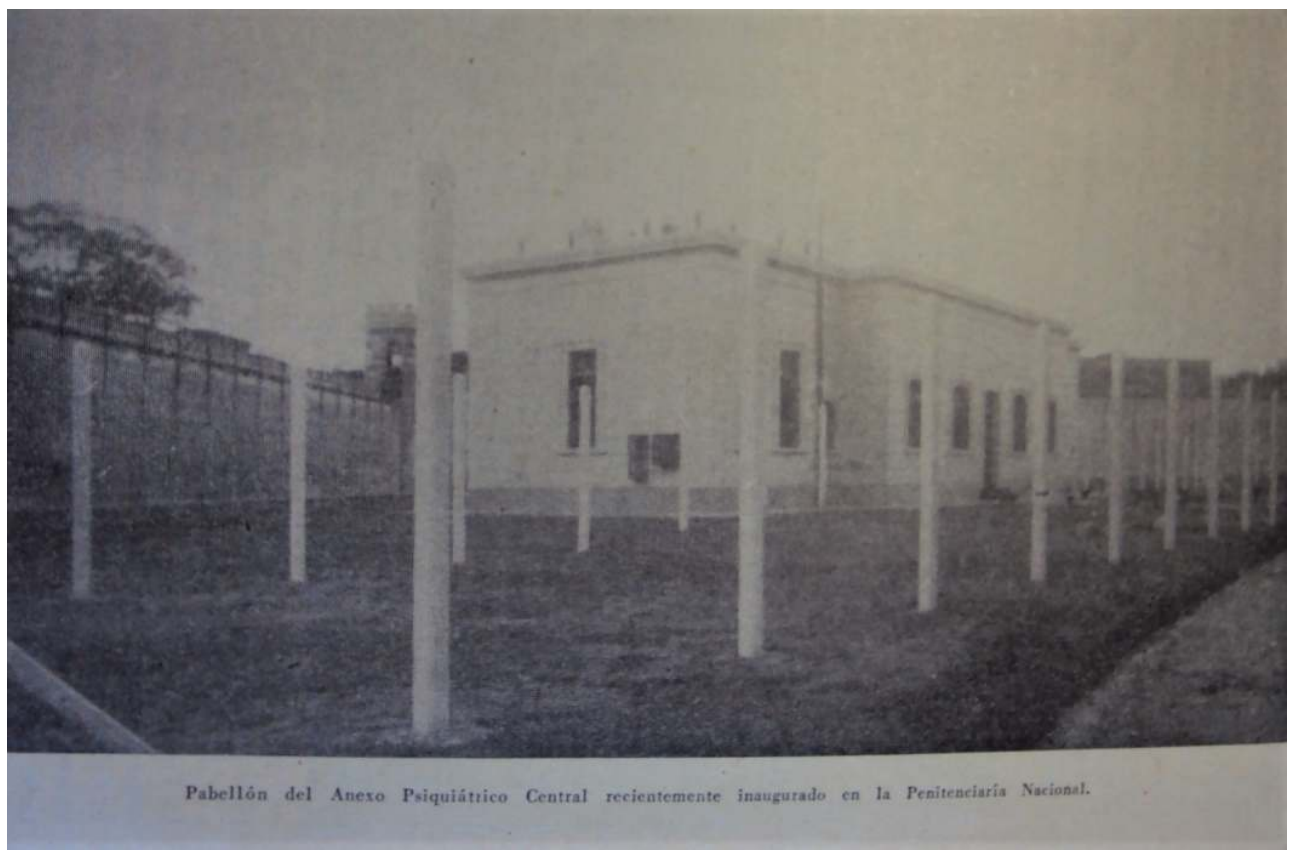

"Inauguración del Anexo Psiquiátrico Central de la Penitenciaría Nacional", RPP, año III, n 7, 1938, p 102.

Por último, la inauguración de la Colonia Penal de Santa Rosa en 1940, obra reclamada por legisladores y penalistas dada la "índole predominantemente agrícola" del país, evidenciaba la concreción de un proyecto que se inició en 1935 bajó la dirección de J. J. O 'Connor, y que concluía la gestión de J. M. Paz Anchorena ${ }^{76}$. La detallada descripción del "moderno establecimiento" estuvo acompañada por los discursos e imágenes de las 
autoridades gubernamentales en el acto de apertura, y diversas fotografías de los oficiales en la puerta del establecimiento, las garitas de seguridad, los extensos campos dedicados a la labor de los penados, el hospital, los talleres de trabajo, el comedor y los dormitorios del personal de seguridad.

La Colonia Penal de la Pampa. Un moderno establecimiento penal argentino

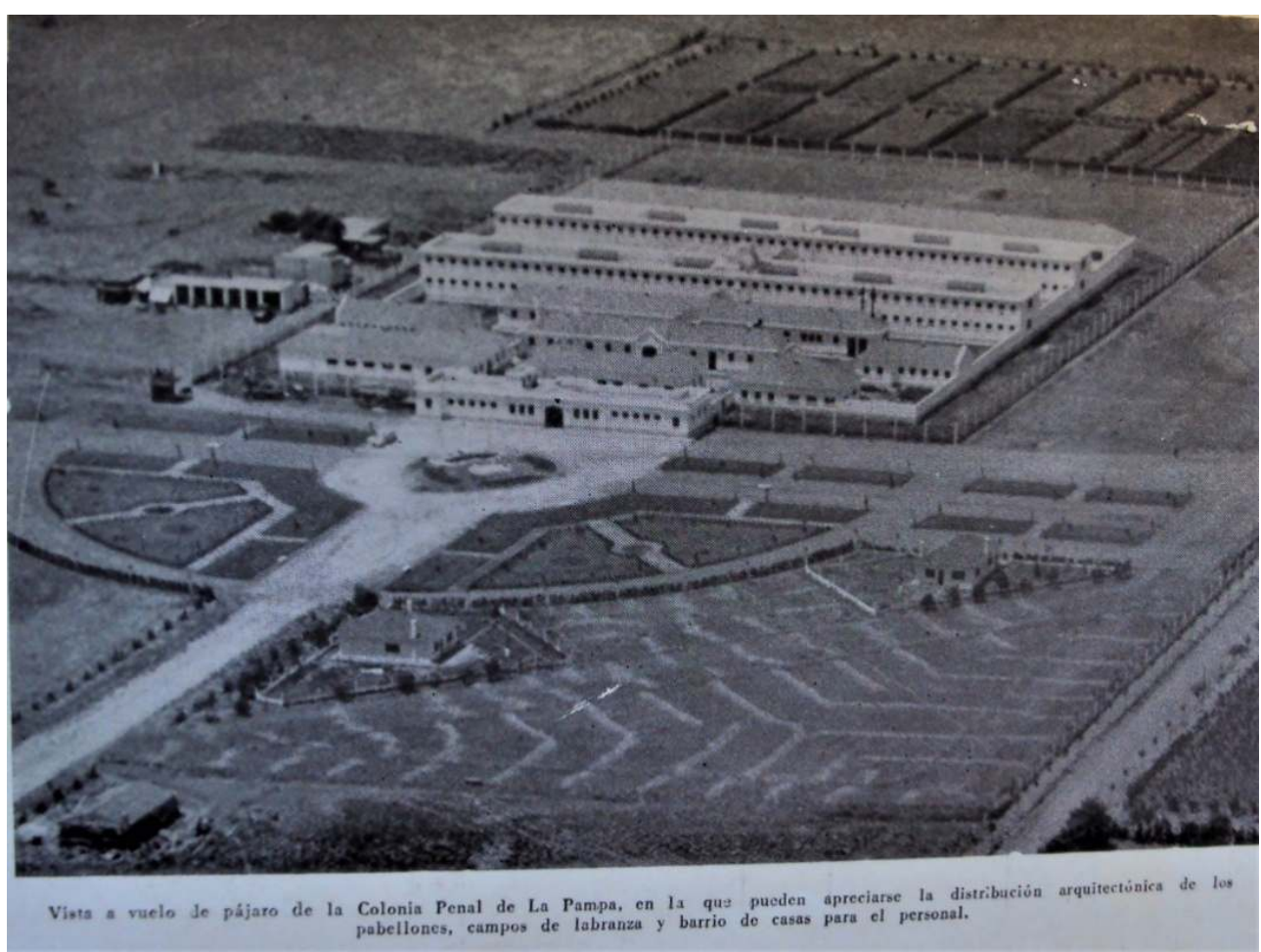

"La Colonia Penal de la Pampa. Un moderno establecimiento penal argentino", RPP, año V, n 15, 1940, p. 159.

En síntesis, la utilización del recurso fotográfico para dar cuenta de los logros penitenciarios y la centralidad que tuvieron los aspectos edilicios en ella, nos permiten aportar un elemento más a la hora de señalar la importancia otorgada por la administración penitenciaria argentina y los funcionarios de la burocracia carcelaria a documentar e informar las obras realizadas. Hacia los años finales de su gestión los conservadores, aún conscientes de que todos los proyectos penales no se habían alcanzado, en gran parte por la situación del erario, la política de austeridad fiscal y las prioridades de la inversión pública en la estructura productiva ${ }^{77}$, la RPP documentaba gracias a la fotografía en su órgano oficial, los importantes cambios logrados en materia penitenciaria.

\section{Conclusiones}

Este artículo se propuso demostrar el lugar destacado que ocupó la Revista Penal y Penitenciaria en el seno de las transformaciones que impulsó la Dirección General de Institutos Penales durante la gestión de sus primeros tres directores entre 1936 y 1946. Así, la breve reconstrucción de la conformación de la DGIP y el perfil de sus Directores Generales permitió comprender el contexto modernizador en el que surgió esta revista, 
así como los objetivos que se propuso alcanzar. Su propuesta, explicitada en el primer número, buscaba conjugar los saberes penitenciarios y penales de los expertos, con la información institucional de la DGIP destinada a los funcionarios.

41 La primera cuestión que ocupó un lugar central en la revista fueron las investigaciones originales. Buscando convertirse en una tribuna de los saberes de la cuestión criminal, sus páginas nos permitieron adentrarnos a las concepciones, ideas y debates a los que la DGIP adscribió y se propuso contribuir durante sus primeros diez años de vida. Reflexiones, pesquisas e intervenciones de los expertos -y en menor medida de los funcionarios-, sobre la reforma de los Códigos Penales, las experiencias carcelarias del país e internacionales, así como las reseñas de los múltiples eventos dedicados a estos temas documentan la fecundidad que tuvieron estas cuestiones durante el periodo estudiado. Cumpliendo este objetivo, la RPP se convirtió en una referencia obligada para los interesados en las problemáticas penales y carcelarias.

Asimismo, la revista constituyó el canal predilecto de las autoridades y funcionarios que buscaron comunicar y difundir la obra de gobierno. No es casual que, en el marco de la nutrida agenda que se tradujo en múltiples proyectos, normativa y transformaciones edilicias, las administraciones diseñasen un instrumento capaz de ofrecer en detalle información considerada relevante. A su turno, en el contexto de crecimiento constante de la burocracia que dependía de la DGIP la revista permitió encontrar toda la información producida por esta nueva repartición. Puede considerarse entonces a la RPP un instrumento eficaz en su tarea de publicitar las políticas penitenciarias y ofrecer a los lectores información sistematizada sobre las innovaciones ocurridas en materia carcelaria. Asimismo, las fotografías sobresalieron en la estrategia comunicativa, ampliando los recursos disponibles y fortaleciendo su capacidad simbólica como agencia moderna. La descripción de todas las acciones de la DGIP, entonces, necesitó de un personal dedicado a cubrir actos, relevar resoluciones administrativas y legales, trascribir discursos y dejar testimonios visuales de las obras en ejecución y finalizas.

43 Así concebida, la RPP alcanzó durante estos años prestigio en la estructura gubernamental y en los ámbitos especializados, tanto a nivel nacional como internacional. Presentada como un logro por los funcionarios, su larga trayectoria durante gran parte del siglo XX es en sí misma testimonio del éxito que alcanzó. Al forjar una práctica utilizada por y para la burocracia carcelaria, su desarrollo constituyó un elemento central e ineludible en el proceso modernizador de las prácticas del castigo en la Argentina de los años 30 y 40.

\section{Fuentes}

Aftalion Enrique \& Alfonsín, Julio, La ejecución de las sanciones penales en la República Argentina, Editorial El Ateneo, Buenos Aires, 1953, 51 p. "Cárceles y Establecimientos de Corrección Nacionales - Se crea una Comisión de superintendencia", Boletín Oficial de la República Argentina, 4 de agosto de 1924, Año XXXII, $\mathrm{n}^{\circ} 9112$.

"Decreto N ${ }^{\circ} 116.813$. Creación del empleo de Subdirector y provisión del mismo", Boletín Oficial de la República Argentina, 20 de septiembre de 1938, Año XLVI, n 13.246, p. 12440.

“Memoria de la Dirección General de Institutos Penales”, RPP, año I, n¹1, 1936, p. 220. 
Congreso Nacional, Diario de sesiones de la Cámara de Diputados. Año 1933. Sesiones Ordinarias, Tomo VI, Imprenta del Congreso Nacional, Buenos Aires, 1934.

Congreso Nacional, Diario de sesiones de la Cámara de Diputados. Año 1933. Sesiones Ordinarias, Tomo VI, Imprenta del Congreso Nacional, Buenos Aires, 1934.

Decreto N 14.312. Dirección General de Institutos Penales. Se efectúan designaciones”, Boletín Oficial de la República Argentina, 1 de diciembre de 1943, Año LX, n 14.767.

Departamento de Justicia. Ministerio de Justicia e Instrucción Pública, Memoria presentada al Honorable Congreso de la Nación. Año 1941, Talleres Gráficos de la Penitenciaría Nacional, Buenos Aires, 1942.

Ministerio de Justicia e Instrucción Pública, Memoria de Departamento de Justicia presentada al Honorable Congreso de la Nación. Año 1936, Talleres Gráficos de la Penitenciaria Nacional, Buenos Aires, 1937.

Ministerio de Justicia e Instrucción Pública, Memoria presentada al Honorable Congreso de la Nación. Departamento de Justicia, Año 1940, Talleres Gráficos de la Penitenciaría Nacional, Buenos Aires, 1941.

Paz Anchorena, José María, Inauguración del Anexo Psiquiátrico Central de la Penitenciaría Nacional, Talleres Gráficos de la Penitenciaría Nacional, Buenos Aires, 1938.

Paz Anchorena, José María, La prevención de la delincuencia. Instituciones de posible adaptación en la República Argentina, Tesis para optar al grado de Doctor en Jurisprudencia, Facultad de Derecho y Ciencias Sociales, Universidad de Buenos Aires, 1917.

Revista Penal y Penitenciaria, números comprendidos entre 1936 y 1946.

Sistema Penitenciario Federal, 50 Aniversario 1933-1983, Editorial Penitenciaria, Buenos Aires, 1984.

\section{BIBLIOGRAFÍA}

Aguirre, Carlos, “Cárcel y sociedad en América Latina. 1800-1940”, Kingman Garcés, Eduardo (ed), Historia social urbana. Espacios y flujos, Flacso-Ministerio de Cultura del Ecuador, Quito, 2009, pp. 209-252.

Alonso, Paula (comp.), Construcciones impresas. Panfletos, diarios y revistas en la formación de los estados nacionales en América Latina, 1820-1920, FCE, Buenos Aires, 2003, 344 p.

Ballent, Anahí \& Gorelik, Adrián, "País urbano o país rural: la modernización territorial y su crisis", Cattaruzza, Alejandro (dir.), Crisis económica, avance del estado e incertidumbre política, Sudamericana, Buenos Aires, 2001, pp. 143-200.

Bohoslavsky, Ernesto \& Casullo, Fernando "Sobre los límites del castigo en la Argentina periférica. La cárcel de Neuquén (1904-1945)”, Quinto Sol, Santa Rosa, n 7, 2003, p. 3-59.

Bohoslavsky, Ernesto \& Di Liscia, María Silvia (comps.), Instituciones y formas de control social en América Latina, 1840-1940, Prometeo libros-UNGS, Buenos Aires, 2005, 220 p. 
Bretas, Marcos Luiz \& Galeano, Diego (coords.), Policías escritores, delitos impresos. Revistas policiales en América del Sur, Editorial Teseo, Buenos Aires, 2017, 504 p.

Briggs, Asa \& Burke, Peter, De Gutenberg a internet. Una historia social de los medios de comunicación, Taurus, Madrid, 2002, 425 p.

Caimari, Lila, "Que la revolución llegue a las cárceles: el castigo en la Argentina de la justicia social (1946-1955)", Entrepasados, Buenos Aires, n²2, 2002, p. 27-48.

Caimari, Lila, Apenas un delincuente. Crimen, castigo y cultura en Buenos Aires, 1880-1940, Siglo XXI, Buenos Aires, 2004, 312 p.

Caimari, Lila, Mientras la ciudad duerme. Pistoleros, policías y periodistas en Buenos Aires, 1920-1945, Siglo XXI editores, Buenos Aires, 2012, 243 p.

Cesano, Daniel, La política penitenciaria durante el primer peronismo (1946-1955): Humanización, clima ideológico e imaginarios, Brujas, Córdoba, 2011, 154 p.

Di Liscia, María Silvia \& Soprano, Germán (ed.), Burocracias estatales. Problemas, enfoques y estudios de caso en la Argentina (entre fines de siglo XIX y XX), Prohistoria/ EdUNLPam, Rosario, 2017, 217 p.

Finocchio, Silvia, La escuela en la historia argentina, Edhasa, Buenos Aires, 2009, 211 p.

Gayol, Sandra \& Palermo, Silvana (ed.), Política y cultura de masas en la Argentina de la primera mitad del siglo XX, Universidad Nacional de General Sarmiento, Los Polvorines, 2018, 344 p.

Gené, Marcela \& Malosetti Costa, Laura (comps.), Atrapados por la imagen. Arte y política en la cultura impresa argentina, Edhasa, Buenos Aires, 2013, 360 p.

Gerchunoff, Pablo \& Llach, Lucas, El ciclo de la ilusión y el desencanto. Un siglo de políticas económicas argentinas, Ariel, Buenos Aires, 1998, 490 p.

Mailhe, Alejandra, "El archivo de Archivos: un latinoamericanismo eurocéntrico en la psiquiatría y la criminología de principios de siglo XX”, Varia Historia, Belo Horizonte, vol. 30, n 54, 2014, pp. 655-678.

Morresi, Sergio \& Vommaro, Gabriel (comps.), Saber lo que se hace. Expertos y políticas en Argentina, Prometero-UNGS, Buenos Aires, 2011, 461 p.

Neiburg Federico \& Plotkin, Mariano (comps.), Intelectuales y expertos. La constitución del conocimiento social en la Argentina, Paidós, Buenos Aires, 2004, 395 p.

Plotkin, Mariano \& Zimmermann, Eduardo (comps.), Los saberes del Estado, Edhasa, Buenos Aires, 2012, 256 p.

Núñez, Jorge, “Algunos comentarios sobre las revistas penitenciarias en España durante la Restauración. Una fuente imprescindible (y olvidada) para el estudio del ordenamiento punitivo (1894-1927)", Revista Electrónica de Fuentes y Archivos, Centro de Estudios Históricos "Prof. Carlos S. A. Segreti", Córdoba, año 4, nº 4, 2013, p. 266-277.

Panella, Claudio \& Korn, Guillermo (comps.), Ideas y debates para la Nueva Argentina. Revistas culturales y políticas del peronismo (1946-1955). Volumen I, EPC-UNLP, La Plata, 2010, 407 p.

Palermo, Silvana, "Los ferrocarriles del estado entre la política electoral y la modernidad administrativa: la revista Riel y Fomento a comienzos de 1920", Revista Estudios del ISHiR, año 2, n 3, 2012, p. 59-83.

Ramacciotti, Karina, "La salud pública se da a conocer publicaciones sanitarias del Estado argentino, 1946-1950”, Apuntes: Revista de Ciencias Sociales, vol. 38, nº 69, 2011, p. 157-180. 
Salvatore, Ricardo, “Criminología positivista, reforma de prisiones y la cuestión social/obrera en Argentina”, Suriano, Juan (comp.), La cuestión social en Argentina. 1870-1943, Editorial La Colmena, Buenos Aires, 2000, pp. 127-158.

Salvatore, Ricardo, "Sobre el surgimiento del estado médico-legal en la Argentina (1890-1940)", Estudios Sociales, Santa Fe, n²0, 2001, pp. 81-114.

Salvatore, Ricardo (ed.), Los lugares del saber, Beatriz Viterbo Editora, Rosario, 2007, 408 p.

Silva, Jeremías, "Difundir el “penitenciarismo justicialista”: La Revista Penal y Penitenciaria 1946-1953”, Panella, Claudio \& Korn, Guillermo (comps.), Ideas y debates para la Nueva Argentina. Revistas culturales y políticas del peronismo (1946-1955). Volumen III, Facultad de Periodismo y Comunicación Social-UNLP, La Plata, 2016, pp. 137-164.

Silva, Jeremías, "El sistema penitenciario del Estado Nacional entre 1930-1943”, Barreneche, Osvaldo \& Salvatore, Ricardo (comps), El delito y el orden en perspectiva histórica, Prohistoria, 2013, Rosario, pp. 227-250.

Silva, Jeremías, “Abandonad toda esperanza, vosotros los que entráis. Proyectos, legislación y políticas penitenciarias en Argentina (1916-1938)”, Caimari, Lila \& Sozzo, Máximo (Comps), Historia de la cuestión criminal en América Latina, Prohistoria, Rosario, 2017, p. 317-356.

Silva, Jeremías, Saberes, reformas y políticas penitenciarias. Argentina y Chile en la primera mitad del siglo XX, Tesis de doctorado en Ciencias Sociales, IDES-UNGS, Buenos Aires, Argentina, 2017, 349 p.

Silva, Jeremías, "Qué todo el mundo sepa lo que ocurre muros adentro de las cárceles: de la reforma penitenciaria del peronismo clásico (1947-1955)", Polhis. Revista Bibliográfica del Programa Interuniversitario de Historia Política, Mar del Plata, $\mathrm{n}^{\circ}$ 22, 2018, pp. 116-155.

Suriano, Juan, "El mundo como un taller de observación. La creación del Departamento Nacional del Trabajo y las influencias internacionales", Revista de Indias, Sevilla, vol. LXXIII, n² 257, 2013, pp. 107-130.

Tell, Verónica, El lado visible. Fotografía y progreso en la Argentina de fines de siglo XIX, UNSAM edita, San Martín, 2017, 336 p.

\section{NOTAS}

1. Departamento de Justicia. Ministerio de Justicia e Instrucción Pública, Memoria presentada al Honorable Congreso de la Nación. Año 1941, Talleres Gráficos de la Penitenciaría Nacional, Buenos Aires, 1942, p. 435. Este artículo se enmarca en el Proyecto de Investigación "Política y cultura en los siglos XIX y XX" (Código 30/1103) radicado en el Instituto de Ciencias de la Universidad Nacional de General Sarmiento, dirigido por la Dra. Sandra Gayol y co-dirigido por la Dra. Silvana Palermo. Agradezco la atenta lectura y los comentarios de Jorge Núñez a una versión previa de este trabajo.

2. Sobre la política penitenciaria del peronismo clásico ver: Caimari, Lila, "Que la revolución llegue a las cárceles: el castigo en la Argentina de la justicia social (1946-1955)”, Entrepasados, Buenos Aires, $n^{\circ}$ 22, 2002, pp. 27-48; Cesano, Daniel, La política penitenciaria durante el primer peronismo (1946-1955): Humanización, clima ideológico e imaginarios, Brujas, Córdoba, 2011. Sobre la RPP: Silva, Jeremías, "Difundir el "penitenciarismo justicialista": La Revista Penal y Penitenciaria 1946-1953", Panella, Claudio \& Korn, Guillermo (comps.), Ideas y debates para la Nueva Argentina. Revistas culturales y políticas del peronismo (1946-1955). Volumen III, Facultad de Periodismo y Comunicación Social-UNLP, La Plata, 2016, pp. 137-164. 
3. Finocchio, Silvia, La escuela en la historia argentina, Edhasa, Buenos Aires, 2009; Palermo, Silvana, "Los ferrocarriles del estado entre la política electoral y la modernidad administrativa: la revista Riel y Fomento a comienzos de 1920", Revista Estudios del ISHiR, año 2, n 3, 2012, pp. 59-83; Ramacciotti, Karina, "La salud pública se da a conocer publicaciones sanitarias del Estado argentino, 1946-1950”, Apuntes: Revista de Ciencias Sociales, vol. 38, n6 6, 2011, pp. 157-180; Panella, Claudio \& Korn, Guillermo (comps.), Ideas y debates para la Nueva Argentina. Revistas culturales y políticas del peronismo (1946-1955), EPC-UNLP, La Plata, 2012; Caimari, Lila, Mientras la ciudad duerme. Pistoleros, policías y periodistas en Buenos Aires, 1920-1945, Siglo XXI editores, Buenos Aires, 2012; Bretas, Marcos Luiz \& Galeano, Diego (coords.), Policías escritores, delitos impresos. Revistas policiales en América del Sur, Editorial Teseo, Buenos Aires, 2017.

4. Núñez, Jorge, “Algunos comentarios sobre las revistas penitenciarias en España durante la Restauración. Una fuente imprescindible (y olvidada) para el estudio del ordenamiento punitivo (1894-1927)", Revista Electrónica de Fuentes y Archivos, Centro de Estudios Históricos "Prof. Carlos S. A. Segreti”, Córdoba, año 4, $\mathrm{n}^{\circ} 4$, 2013, pp. 266-277; Silva, J., "Difundir el penitenciarismo justicialista", Op. Cit.

5. Congreso Nacional, Diario de sesiones de la CJmara de Diputados. Ao̊ 1933. Sesiones Ordinarias, Tomo VI, Imprenta del Congreso Nacional, Buenos Aires, 1934, p. 478-480.

6. Silva, Jeremías, “Abandonad toda esperanza, vosotros los que entráis. Proyectos, legislación y políticas penitenciarias en Argentina (1916-1938)”, Caimari, Lila \& Sozzo, Máximo (Comps), Historia de la cuestión criminal en América Latina, Prohistoria, Rosario, 2017, p. 317-356.

7. Silva, Jeremías, "El sistema penitenciario del Estado Nacional entre 1930-1943", Barreneche, Osvaldo \& Salvatore, Ricardo (comps), El delito y el orden en perspectiva histórica, Prohistoria, 2013, Rosario, pp. 227-250.

8. Cárcel de Ushuaia (Territorio Nacional de Tierra del Fuego); Cárcel de Resistencia (Territorio Nacional de Chaco); Cárcel de Posadas (Territorio Nacional de Misiones); Cárcel de Formosa (Territorio Nacional de Formosa); Cárcel de Santa Rosa (Territorio Nacional de la Pampa); Cárcel de Neuquén (Territorio Nacional de Neuquén); Cárcel de Viedma (Territorio Nacional de Río Negro); Cárcel de Río Gallegos (Territorio Nacional de Santa Cruz); Cárcel de Rawson (Territorio Nacional de Chubut). En 1934 se inauguró la Cárcel de General Roca (Territorio Nacional de Río Negro) y la Cárcel de Esquel (Territorio Nacional de Chubut), mientras que en 1935 la Cárcel de General Pico (Territorio Nacional de la Pampa). Por último, en 1940 se constituyó la Colonia Penal de La Pampa.

9. Caimari, Lila, Apenas un delincuente. Crimen, castigo y cultura en Buenos Aires, 1880-1940, Siglo XXI, Buenos Aires, 2004; Salvatore, Ricardo, “Criminología positivista, reforma de prisiones y la cuestión social/obrera en Argentina", Suriano, Juan (comp.), La cuestión social en Argentina. 1870-1943, Editorial La Colmena, Buenos Aires, 2000, pp. 127-158; Salvatore, Ricardo, "Sobre el surgimiento del estado médico-legal en la Argentina (1890-1940)", Estudios Sociales, Santa Fe, $\mathrm{n}^{\circ}$ 20, 2001, pp. 81-114.

10. Congreso Nacional, Diario de sesiones de la CJmara de Diputados. Aô 1933. Sesiones Ordinarias, Tomo VI, Imprenta del Congreso Nacional, Buenos Aires, 1934, p. 479.

11. "Cárceles y Establecimientos de Corrección Nacionales - Se crea una Comisión de superintendencia", Boletsn Oficial de la Repblica Argentina, 4 de agosto de 1924, Año XXXII, nº 9112, p. 71.

12. González Millán, Ángel, “Significado de la obra del Dr. Juan José O'Connor”, Revista Penal y Penitenciaria (RPP), año VII, $n^{\circ} 24,1942$, pp. 232-231.

13. Paz Anchorena, José María, La prevención de la delincuencia. Instituciones de posible adaptación en la República Argentina, para optar al grado de Doctor en Jurisprudencia, Facultad de Derecho y Ciencias Sociales, Universidad de Buenos Aires, 1917.

14. Quién es quién en la Argentina. Biografías contemporáneas, Buenos Aires, 1963, p. 557. 
15. Ministerio de Justicia e Instrucción Pública, Memoria de Departamento de Justicia presentada al Honorable Congreso de la Nación. Año 1936, Talleres Gráficos de la Penitenciaria Nacional, Buenos Aires, 1937, p. 140.

16. “Decreto $\mathrm{N}^{\circ} 116.813$. Creación del empleo de Subdirector y provisión del mismo", Boletsn Oficial de la Repblica Argentina, 20 de septiembre de 1938, Año XLVI, nº 13.246, p. 12440.

17. "Decreto $\mathrm{N}^{\circ}$ 14.312. Dirección General de Institutos Penales. Se efectúan designaciones", Boletsn Oficial de la Repblica Argentina, 1 de diciembre de 1943, Año LX, n 14.767, p. 2.

18. "Memoria de la Dirección General de Institutos Penales", RPP, año I, n¹, 1936, p. 220.

19. Caimari, L., Apenas un delincuente, Op. Cit.; Bohoslavsky, Ernesto \& Casullo, Fernando "Sobre los límites del castigo en la Argentina periférica. La cárcel de Neuquén (1904-1945)", Quinto Sol, Santa Rosa, n 7, 2003, pp. 3-59; Bohoslavsky, Ernesto \& Di Liscia, María Silvia, Instituciones y formas de control social en América Latina, 1840-1940, Prometeo libros-UNGS, Buenos Aires, 2005.

20. Este número comprendía el personal de la Plana superior (Director, Subdirector, Inspector, Alcaides, prefectos), Plana Inferior (suboficiales, sargentos, cabos, guardias) y Personal Asimilado (docentes, médicos, odontólogos, practicantes, maestranza). Ministerio de Justicia, Memoria y estadística. 1947. Dirección General de Institutos Penales, Talleres Gráficos de la D.G.I.P, Buenos Aires, 1949, pp. 177-178.

21. "Dirección General de Institutos Penales - Estableciendo el reglamento orgánico de la misma”, RPP, año I, n¹, 1936, p. 134.

22. Alonso, Paula (comp.), Construcciones impresas. Panfletos, diarios y revistas en la formación de los estados nacionales en América Latina, 1820-1920, FCE, Buenos Aires, 2003.

23. Briggs, Asa \& Burke, Peter, De Gutenberg a internet. Una historia social de los medios de comunicación, Taurus, Madrid, 2002, pp. 213-297.

24. Gayol, Sandra \& Palermo, Silvana (ed.), Política y cultura de masas en la Argentina de la primera mitad del siglo XX, Universidad Nacional de General Sarmiento, Los Polvorines, 2018.

25. Como señalan acertadamente María Di Liscia y Germán Soprano, los estudios dedicados específicamente a las burocracias son pocos y recientes en la historiografía Argentina, aunque están cobrando mayor interés: Di Liscia, María Silvia \& Soprano, Germán (ed.), Burocracias estatales. Problemas, enfoques y estudios de caso en la Argentina (entre fines de siglo XIX y XX), Prohistoria, Rosario, 2017. En este mismo sentido ver las contribuciones que forman parte del dossier: Palermo, Silvana \& Silva, Jeremías, "Expertos, burocracias y política de masas en Argentina", Estudios sociales del Estado, vol 2, n 3, 2016.

26. Mailhe, Alejandra, "El archivo de Archivos: un latinoamericanismo eurocéntrico en la psiquiatría y la criminología de principios de siglo XX", Varia Historia, Belo Horizonte, vol. 30, n 54, 2014, pp. 655-678.

27. "Palabras iniciales", RPP, año I, n¹, 1936, p 3.

28. "Palabras iniciales”, RPP, año I, n¹, 1936, p 4. El subrayado es nuestro.

29. Como ya se ha señalado, la gestión carcelaria de los años 30 tuvo una clara impronta cientificista, adhiriendo a las premisas de la criminología positivista: Salvatore, R., "Sobre el surgimiento del estado...”, Op. Cit.; Silva, J., “Abandonad toda esperanza...”, Op. Cit.

30. Soler, Sebastián, “Anteproyecto del Código de Faltas de la Provincia de Santa Fe", RPP, año I, $\mathrm{n}^{\circ}$ 2, 1936, pp. 307-336.

31. Paz Anchorena, José María \& Silva Riestra, Juan \& Viale, Atilio \& Etcheverry, César, "Régimen e institutos carcelarios de la Provincia de Buenos Aires”, RPP, año I, n² 2, 1936, pp. 337-360.

32. Spota, Benjamín, “Emoción violenta ante el Código Penal”, RPP, año II, n 3, 1937, pp. 17-20.

33. Paz Anchorena, José María "Un periódico para reclusos", RPP, año II, n 6, 1937, pp. 595-614.

34. Silva Riestra, Juan, "Los establecimientos carcelarios franceses”, RPP, año IV, n 13, 1939, pp. 399-414.

35. Stanchina, Camilo, "Creación de una Comisión Especial de Legislación Carcelaria", RPP, año V, $\mathrm{n}^{\circ} 17,1940$, pp. 375-382. 
36. Ramos, Juan, "La Acción del Patronato de liberados", RPP, año VIII, n 29-30, 1943, pp. 469-476.

37. Arenal, Concepción, “¿Qué es el penado?”, RPP, año I, n 1, 1936, pp. 195-200; “John Howard a un siglo de su muerte" RPP, año V, n 15, 1940, pp. 1-18; "10 Aniversario de la muerte de Enrique Ferri", RPP, año IV, n 12, 1939, pp. 337-343; "Homenaje al fundador de la Cárcel de Ushuaia", RPP, año III, $n^{\circ}$ 9, 1938, pp. 531-532.

38. De Yuliis, Mariano, "Consideraciones prácticas para el ensayo de un nuevo tipo de racionamiento en las cárceles de los Territorios Nacionales”, RPP, año II, n 3, 1937, pp. 41-72.

39. Escudero, Pedro, "La alimentación de los presos en las cárceles de los Territorios Nacionales", RPP, año II, n³, 1937, pp. 21-40.

40. Ernesto Grassi, "Un plan racional de educación carcelaria”, RPP, año II, n 6, 1937, pp. 629-658.

41. "Doctor Jorge Eduardo Coll - Excmo. Señor Ministro de Justicia e Instrucción Pública", RPP, año III, n 7, 1938, pp. 3-4; "Dr. Guillermo Rothe. Nuevo Ministro de Justicia e Instrucción Pública”, RPP, año V, n 17, 1940, p. 345-346.

42. "Nuevo Director General de Institutos Penales. El profesor Dr. José María Paz Anchorena", RPP, año II, n 4, 1937, pp. 423-424; "El Doctor Eduardo A. Ortiz se hace cargo de la Dirección General de Institutos Penales", RPP, año VI, n 19, 1941, p. 204.

43. "Demostración al Doctor O'Connor", RPP, año II, n 4, 1937, p. 425.

44. "El ex Director General de Institutos Penales. Dr. José María Paz Anchorena”, RPP, año VI, n 19, 1941 , p. 3.

45. Aftalion Enrique \& Alfonsín, Julio, La ejecución de las sanciones penales en la República Argentina, Editorial El Ateneo, Buenos Aires, 1953; Sistema Penitenciario Federal, 50 Aniversario 1933-1983, Editorial Penitenciaria, Buenos Aires, 1984.

46. Neiburg Federico \& Plotkin, Mariano (comps.), Intelectuales y expertos. La constitución del conocimiento social en la Argentina, Paidós, Buenos Aires, 2004; Plotkin, Mariano \& Zimmermann, Eduardo (comps.), Los saberes del Estado, Edhasa, Buenos Aires, 2012.

47. Salvatore, Ricardo (ed.), Los lugares del saber, Beatriz Viterbo Editora, Rosario, 2007; Morresi, Sergio \& Vommaro, Gabriel (comps.), Saber lo que se hace. Expertos y políticas en Argentina, Prometero-UNGS, Buenos Aires, 2011; Suriano, Juan, "El mundo como un taller de observación. La creación del Departamento Nacional del Trabajo y las influencias internacionales", Revista de Indias, Sevilla, vol. LXXIII, n² 257, 2013, pp. 107-130.

48. "La obra de la Comisión Internacional Penal y Penitenciaria 1872-1942", RPP, Año VII, N²4, 1943, pp. 247-270. Traducción de la RPP del número X de la "Recueil de Documents en matière pénale et pénitentiaire"; "Delegación argentina ante la Comisión Internacional Penal y Penitenciaria”, RPP, año IV, n 11, 1939, p. 146; "La enseñanza profesional de los funcionarios penitenciarios. Informe de la Comisión Internacional Penal y Penitenciaria”, RPP, año 3, $\mathrm{n}^{\circ} 7$, 1938, pp. 27-38.

49. “Conjunto de reglas para el tratamiento de los presos", RPP, año I, nº 2, 1936, pp. 361-370.

50. “Código Penal de la República de Costa Rica”, RPP, año II, n 3, 1937, pp. 439-480.

51. "Reglamento Orgánico del Instituto Nacional de Clasificación y Criminología de la Dirección General de Chile", RPP, año II, n 4, 1937, pp. 287-290.

52. “Código Penal brasileño de 1940”, RPP, año VII, n² 26, 1942, pp. 633-692.

53. "Séptima Conferencia Internacional para la Unificación del Derecho Penal”, RPP, año III, $n^{\circ} 7$, 1938, pp. 48-50; "Primer Congreso Internacional de Criminología (Roma, 1938)”, RPP, año III, $n^{\circ} 7$, 1938, pp. 51-54; “XII Congreso Penal y Penitenciario Internacional (Programa)”, RPP, año III, $n^{\circ}$ 10, 1938, pp. 587-596; “Segunda Conferencia Interamericana de Abogados”, RPP, año VIII, n 29 y 30, 1943, pp. 519-520.

54. "Primer Congreso Latino-Americano de Criminología", RPP, año III, n 8, 1938, pp. 177-180; "Segundo Congreso Latino-Americano de Criminología. Temas y Delegados", RPP, año V, n 18, 
1940, pp. 579-582; "Segundo Congreso Latino-Americano de Criminología”, RPP, año VI, n 19, 1941, pp. 101-122; Coll, Jorge, "El Segundo Congreso Latino-Americano de Criminología”, RPP, año VI, $n^{\circ} 19,1941$, pp. 7-12.

55. Sobre los Congresos Latinoamericanos de Criminología: Silva, Jeremías, Saberes, reformas y políticas penitenciarias. Argentina y Chile en la primera mitad del siglo XX, Tesis de doctorado en Ciencias Sociales, IDES-UNGS, Buenos Aires, Argentina, 2017.

56. "Visita del Director de Prisiones de Chile, Manuel Jara Cristi" y "Visita del Director de Institutos Penales del Uruguay, Doctor Juan C. Gómez Folle”, RPP, año I, n 1, 1936, pp. 265 y 266; "Visitó los establecimientos penales argentinos el Director General de Prisiones de Chile", RPP, año VI, n²1, 1941, pp. 685-692.

57. A modo de ejemplo ver: Gómez Folle, Juan Carlos, "Ley de represión de la vagancia, mendicidad y estados afines", RPP, año II, n 3, 1937, pp. 117-138; “Chile. Proyecto de un Congreso Penitenciario Panamericano", RPP, año II, n 4, 1937, pp. 417-418; "Proyecto chileno de Ley sobre Estados antisociales y medidas de seguridad”, RPP, año VI, n² 21, 1941, pp. 663-674; Olavarría Ávila, Julio, “Descripción de la organización carcelaria chilena”, RPP, año VI, n² 20, 1941, pp. 237-254.

58. “Organización carcelaria y régimen de la pena. Proyecto de ley $\mathrm{N}^{\circ} 11.833$ ”, RPP, año I, $\mathrm{n}^{\circ} 1$, 1936, pp. 113-135.

59. Aguirre, Carlos, "Cárcel y sociedad en América Latina. 1800-1940”, Kingman Garcés, Eduardo (ed), Historia social urbana. Espacios y flujos, Flacso-Ministerio de Cultura del Ecuador, Quito, 2009, pp. 216-217.

60. "Plan de traslado de la Penitenciaría Nacional y construcción de dos colonias penales", RPP, año III, n 9, 1938, pp. 313-376.

61. "Rindiose homenaje a los empleados caídos en el cumplimiento del deber", RPP, año I, $\mathrm{n}^{\circ} 2$, 1936, pp. 529-532.

62. "En la Penitenciaría Nacional. Acto cultural dedicado a los penados", RPP, año II, $\mathrm{n}^{\circ}$ 5, 1937, pp. 565-566.

63. "Viaje de Inspección del Director a Ushuaia (Inauguración de un Mástil)”, RPP, año III, n 7, 1938, 106-107.

64. "Inauguración de talleres en la Cárcel de Mujeres", RPP, año III, n 10, 1938, p. 660.

65. "Fiestas y actos conmemorativos", RPP, año I, n 1, 1936, p. 257.

66. "Fichero general del penado", RPP, año I, n² 2, 1936, pp. 517-523; "Reglamento del Hospital Penitenciario Central", RPP, año V, n 15, 1940, pp. 35-47; "El Poder Ejecutivo de la Nación reglamenta la distribución del producto del trabajo de los penados", RPP, año VIII, n 29 y 30 , 1943, pp. 549-553.

67. O'Connor, Juan José, “Sobre política carcelaria”, RPP, año I, n² 2, 1936, pp. 513-516.

68. Ballent, Anahí \& Gorelik, Adrián, "País urbano o país rural: la modernización territorial y su crisis", Cattaruzza, Alejandro (dir.), Crisis económica, avance del estado e incertidumbre política, Sudamericana, Buenos Aires, 2001, p. 154.

69. Ministerio de Justicia e Instrucción Pública, Memoria presentada al Honorable Congreso de la Nacin̄. Departamento de Justicia, Ao̊ 1940, Talleres Gráficos de la Penitenciaría Nacional, Buenos Aires, 1941, p. 375.

70. Tell, Verónica, El lado visible. Fotografía y progreso en la Argentina de fines de siglo XIX, UNSAM edita, San Martín, 2017, p. 138.

71. Tell, V., El lado visible, Op. Cit.

72. Gené, Marcela \& Malosetti Costa, Laura (comps.), Atrapados por la imagen. Arte y política en la cultura impresa argentina, Edhasa, Buenos Aires, 2013.

73. Silva, Jeremías, "Qué todo el mundo sepa lo que ocurre muros adentro de las cárceles: de la reforma penitenciaria del peronismo clásico (1947-1955)", Polhis. Revista Bibliográfica del Programa Interuniversitario de Historia Política, Mar del Plata, n²2, 2018, pp. 116-155. 
74. "Discurso pronunciado por el Director General de Institutos Penales de la Nación. Doctor José María paz Anchorena", RPP, ao̊ III, n 7, 1938, . 99-104.

75. Paz Anchorena, José María, Inauguración del Anexo Psiquiátrico Central de la Penitenciaría Nacional , Talleres Gráficos de la Penitenciaría Nacional, Buenos Aires, 1938, p. 5.

76. "La Colonia Penal de la Pampa. Un moderno establecimiento penal argentino", RPP, año V, $n^{\circ}$ 15, 1940, pp. 155-178 y “Crónica de la inauguración de la Colonia Penal”, RPP, año V, n 16, 1940, pp. 321-328.

77. Gerchunoff, Pablo \& Llach, Lucas, El ciclo de la ilusión y el desencanto. Un siglo de políticas económicas argentinas, Ariel, Buenos Aires, 1998, pp. 133-136.

\section{RESÚMENES}

El objetivo de este artículo es indagar la Revista Penal y Penitenciaria, el "órgano de difusión" de la Dirección General de Institutos Penales de Argentina, desde su conformación en 1936 hasta el advenimiento del peronismo en 1946, cuando inició una nueva etapa. La revista se consagró como un instrumento clave de la burocracia carcelaria por más de cincuenta años, trascendiendo la gestión de los gobiernos conservadores. En este trabajo, argumentaremos que la revista cumplió un rol central para comprender la modernidad de esta agencia en sus primeros años y constituyó la principal herramienta para los funcionarios: difundió la obra de gobierno, comunicó las medidas implementadas tanto a nivel nacional como provincial, motorizó debates entre expertos y funcionarios, y constituyó un medio relevante para informar las transformaciones legales y legislativas.

The purpose of this article is to investigate the Revista Criminal y Penitenciaria as "diffusion agent" of the Dirección General de Institutos Penales de Argentina, from its debut in 1936 until the emergence of Peronism in 1946. The journal was enshrined as a key instrument of prison bureaucracy for over fifty years, transcending the management of conservative governments. In this paper, we will argue that the journal played a central role in understanding the modernity of this agency in its early years and was an important tool for officials: it disseminated the work of government, communicated the measures implemented at both national and provincial levels, triggered debates between experts and officials, and was a relevant means of informing legal and legislative transformations.

Le but de cet article est d'enquêter sur la Revista Penal y Penitenciaria, l'organe de diffusion de la Direction Générale des Instituts Pénitentiaires d'Argentine, depuis sa conformation en 1936 jusqu'à l'avènement du péronisme en 1946, quand une nouvelle étape a commencé. La revue a été consacrée comme un instrument clé de la bureaucratie carcérale pendant plus de cinquante ans, transcendant la gestion des gouvernements conservateurs. Dans cet article, nous verrons que la revue a joué un rôle central dans la compréhension de la modernité de cet organisme à ses débuts et qu'elle a été le principal outil des fonctionnaires : elle a diffusé les travaux du gouvernement, communiqué les mesures mises en œuvre aux niveaux national et provincial, suscité des débats entre experts et fonctionnaires, et constitué un moyen pertinent de contribuer aux transformations juridiques et législatives. 
ÍNDICE

Palabras claves: estado, revista, cárcel, Argentina, siglo XX

Keywords: state, prison, Argentina, journal, XXth century

Mots-clés: état, prison, Argentine, revue, XXe siècle

\section{AUTOR}

\section{JEREMÍAS SILVA}

Profesor en Historia (2006) y Doctor en Ciencias Sociales (2017) por la Universidad Nacional de General Sarmiento. Investigador Docente del Instituto de Ciencias de la Universidad Nacional de General Sarmiento. Becario Posdoctoral del Consejo Nacional de Investigaciones Científicas y Técnicas de Argentina, CONICET. Correo electrónico: silva.jeremias[at]gmail.com 